\title{
Gastric emptying after oesophagectomy as assessed by plasma paracetamol concentrations
}

\author{
P GOLDSTRAW, P BACH
}

From the Department of Thoracic Surgery, King George V Hospital, and Department of Pharmacology, Medical Faculty, University of Natal, Durban, South Africa

ABSTRACT Gastric emptying after oesophagogastrectomy may be affected by opposing influences. Truncal vagotomy of the orthotopic stomach, as used by surgeons for peptic ulcer, results in delayed gastric emptying. The emptying of such a denervated stomach is affected by position and posture and may result in gastric "incontinence", particularly if associated with drainage procedures. It is possible that postural effects may outweigh the reduced motility if the vagotomised stomach is transplanted into the chest as after oesophagogastrectomy. Despite the effect that disturbed gastric emptying may have on nutrition and drug absorption there have been few studies concerning patients who have had oesophageal resection or bypass. We report our preliminary experience of an indirect method to estimate gastric emptying after oesophageal resection and bypass, using the absorption profile of paracetamol (acetaminophen). This technique is safe and has been shown to reflect gastric emptying accurately in the innervated stomach. With this technique we have shown that, even in the absence of a concomitant drainage procedure, oesophageal resection, or bypass, using the denervated stomach to restore alimentary continuity does not result in any detectable delay in gastric emptying.

Excision of the thoracic oesophagus and its replacement with a gastric tube had been performed successfully for over $\mathbf{4 0}$ years $^{1}$ and is the favoured operation for carcinoma of the oesophagus and gastric cardia. Several operations have been devised, ${ }^{2-5}$ but all have the common aim of radically resecting the tumour-bearing area and using the mobilised stomach to restore continuity. The block dissection of the mediastinum must inevitably result in a complete vagotomy. Controversy continues over the type of drainage procedure necessary for such a denervated stomach and whether one is necessary at all.

Methods for measuring gastric emptying have inherent inaccuracies or limitations. ${ }^{6-9}$ Heading et $a^{10}$ have demonstrated the dependence of paracetamol (acetaminophen) absorption on gastric emptying rate, and Nimmo et $a^{11-13}$ have shown the reproducibility and usefulness of this technique to measure gastric emptying. It is safe and simple, requiring only the administration of a therapeutic dose of paracetamol, and the estimation of paracetamol concentrations in plasma. Since paracetamol is not absorbed from the stomach but is absorbed Address for reprint requests: Mr P Goldstraw, Brompton Hospital, Fulham Road, London SW3 6HP. rapidly from the small bowel, its rate of absorption after oral administration is an indirect measure of the rate of gastric emptying. Rapid paracetamol absorption indicates rapid gastric emptying and slow absorption reflects delayed gastric emptying. This method was used to study gastric emptying after oesophagectomy.

\section{Patients and methods}

CONTROL GROUP

Five patients without evidence of gastrointestinal disease formed a control group. They were men (four African, one Asian) aged 30-55 years (mean 44.4 years), convalescing after minor surgical procedures for pleural sepsis.

STUDY GROUP

Fifteen patients who had previously undergone oesophagectomy, oesophagogastrectomy, or palliative oesophageal bypass were studied. All 15 were given paracetamol orally and five of them were given paracetamol by duodenal tube. All were Africannine men aged 35 to 67 years (mean 50.8 years) and six women aged 40 to 67 years (mean 50.0 years). Eight patients were studied within one month, four from one to three months and three from three 
months to two years after operation. The pylorus had not been surgically impaired in any of these patients. The procedures performed and the sites of anastomoses are shown in table 1.

Table 1 Operation and site of anastomosis in study groups

\begin{tabular}{llll}
\hline Site of anastomosis & Resection & $\begin{array}{l}\text { Attempted } \\
\text { resection } \\
\text { and bypass }\end{array}$ & $\begin{array}{l}\text { Substernal } \\
\text { bypass }\end{array}$ \\
\hline Thoracic $\left\{\begin{array}{llll}\text { low } & 1 & 1 & - \\
\text { at aortic arch } & 9 & - & - \\
\text { above aortic arch } & 2 & - & -\end{array}\right.$ \\
Cervical
\end{tabular}

After an overnight fast, all patients received paracetamol $1200 \mathrm{mg}$ as $50 \mathrm{ml}$ of paediatric solution (Panadol syrup) followed by $20-30 \mathrm{ml}$ of water. All medications had been discontinued for 24 hours before the study. No food, fluid, or tobacco ${ }^{14}$ were allowed for three hours and the subjects remained supine in bed during the study (it proved impractical to dictate either lateral position). ${ }^{15}$

In the duodenal group, the nasogastric tube was swallowed on the evening before the study and its position in the duodenum confirmed radiologically immediately before the study.

Blood samples were taken at intervals for 24 hours and paracetamol concentrations were measured in duplicate by gas liquid chromatography. ${ }^{16} 17$

Data were analysed by the Mann-Whitney $U$ test. ${ }^{18}$ Areas under the plasma concentration-time curves were calculated using the trapezoid rule.

\section{Results}

Paracetamol absorption and hence gastric emptying was normal in all control studies (table 2, figure). The mean peak plasma paracetamol concentration was $10.2 \pm 2.4 \mu \mathrm{g} / \mathrm{ml}( \pm \mathrm{SE})$ and was achieved 60 minutes after administration. Allowing for the differences in the dose this is comparable with that observed in previous studies. ${ }^{10} 12$

After oesophagectomy, the mean peak plasma paracetamol concentration was $7 \cdot 5 \pm 2.0 \mu \mathrm{g} / \mathrm{ml}$ and

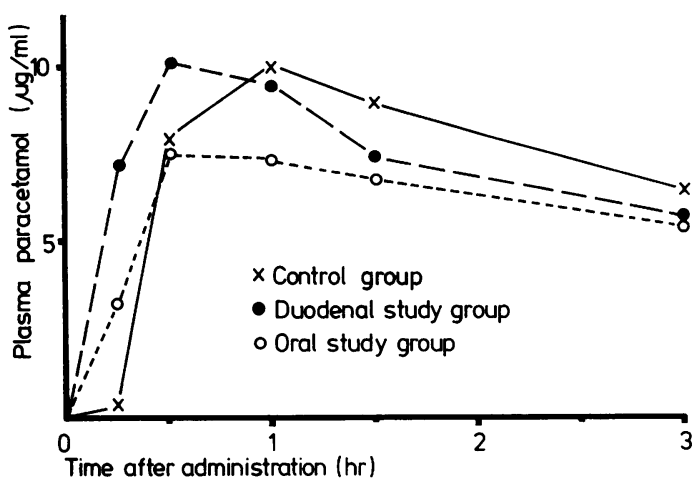

Figure Mean plasma paracetamol concentrations after oesophagogastrectomy.

occurred 30 minutes after administration. There was a trend towards lower plasma concentrations than in the control group, but at no time did the concentrations differ significantly from the control group. In particular, paracetamol absorption was faster than has been reported in subjects receiving propantheline or narcotic analgesics which markedly delay gastric emptying. ${ }^{10-13}$ After duodenal instillation of paracetamol to patients after oesophagectomy, a mean peak plasma concentration of $10 \cdot 1 \pm 1.6 \mu \mathrm{g} / \mathrm{ml}$ was achieved 30 minutes after administration. Concentrations did not differ significantly from those obtained after oral administration.

The areas under the plasma concentration-time curves from 0 to 24 hours (AUC) did not differ significantly in the three groups. Thus bioavailability of the drug was probably not influenced by oesophagectomy.

\section{Discussion}

In the present study, paracetamol absorption after oral administration was not influenced by oesophagectomy and in fact did not differ significantly from absorption after duodenal instillation. Therefore gastric emptying was not significantly delayed by oesophagectomy with vagotomy.

Table 2 Mean plasma paracetamol concentrations $\pm S E^{*}$ after oesophagogastrectomy. Each subject received $1 \cdot 2 \mathrm{~g}$ as $50 \mathrm{ml}$ paediatric solution with $30 \mathrm{ml}$ of water

\begin{tabular}{|c|c|c|c|c|c|c|c|c|}
\hline \multirow[t]{2}{*}{ Group } & \multicolumn{7}{|c|}{ Plasma paracetamol concentration $(\mu \mathrm{g} / \mathrm{ml})$} & \multirow{2}{*}{$\begin{array}{l}A U C \dagger \\
0-24 h r \\
\mu g / m l / h r\end{array}$} \\
\hline & $15 \mathrm{~min}$ & $30 \mathrm{~min}$ & $60 \mathrm{~min}$ & $90 \min$ & $3 h r$ & $5 \mathrm{hr}$ & $8 h r$ & \\
\hline $\begin{array}{l}\text { Control } \\
\mathrm{n}=5 \\
\text { Oral study } \\
\mathrm{n}=15 \\
\text { Duodenal study } \\
\mathrm{n}=5\end{array}$ & $\begin{array}{c}0 \cdot 23 \\
\pm 0 \cdot 23 \\
3 \cdot 2 \\
\pm 1 \cdot 1 \\
7 \cdot 1 \\
\pm 3 \cdot 6\end{array}$ & $\begin{array}{r}7.9 \\
+\quad 1.4 \\
7.5 \\
+2.0 \\
10 \cdot 1 \\
\pm 1 \cdot 3\end{array}$ & $\begin{array}{r}10 \cdot 2 \\
\pm 2 \cdot 4 \\
7 \cdot 3 \\
\pm 1 \cdot 6 \\
9 \cdot 5 \\
\pm 1 \cdot 9\end{array}$ & $\begin{array}{r}8 \cdot 9 \\
\pm 2 \cdot 1 \\
6 \cdot 8 \\
\pm 1 \cdot 3 \\
7 \cdot 4 \\
\pm 1 \cdot 3\end{array}$ & $\begin{array}{r}6 \cdot 4 \\
\pm 1 \cdot 3 \\
5 \cdot 4 \\
\pm 0 \cdot 5 \\
5 \cdot 7 \\
\pm 1 \cdot 1\end{array}$ & $\begin{array}{r}5 \cdot 5 \\
\pm 1 \cdot 1 \\
4 \cdot 2 \\
\pm 0 \cdot 5 \\
6 \cdot 1 \\
\pm 1 \cdot 4\end{array}$ & $\begin{array}{c}3.5 \\
\pm 0.63 \\
2.7 \\
\pm 0.31 \\
3.2 \\
\pm 0.5\end{array}$ & $\begin{array}{r}48 \cdot 8 \\
\pm 7 \cdot 8 \\
38 \cdot 9 \\
\pm 5 \cdot 1 \\
47 \cdot 7 \\
\pm 8 \cdot 2\end{array}$ \\
\hline
\end{tabular}

*SE = standard error.

†AUC = area under the plasma concentration-time curve. 
Although the plasma paracetamol concentrations in the study group were slightly lower than in the control subjects, there were no statistically significant differences in the plasma concentrations or the areas under the plasma concentration-time curves between the two groups. In addition, plasma concentrations and time of peak plasma concentrations were similar to those previously reported in healthy volunteers, and paracetamol absorption was faster than that reported in subjects receiving propantheline. ${ }^{10-13}$

Oesophagectomy had become established by the time that Dragstedt ${ }^{19}$ reported his early results with vagotomy in the treatment of peptic ulcers, in which the consequent decrease in gastric motility was considered of therapeutic benefit. Realising that gastric drainage was necessary after truncal vagotomy for ulcer surgery, ${ }^{20} 21$ thoracic surgeons have assumed that formal drainage was also necessary after the incidental vagotomy incurred at oesophagectomy. ${ }^{22}$ Current opinion ${ }^{23-25}$ recommends a drainage procedure with oesophagectomy, but there are reports where gastric emptying is satisfactory on clinical evaluation and formal testing ${ }^{26} 27$ in the absence of any drainage procedure. In the reported series the pylorus has been left inviolate if normal, ${ }^{26} 27$ subjected to digital dilatation, ${ }^{4} 28$ pyloromyotomy, ${ }^{329-31}$ or formal pyloroplasty. ${ }^{22} 3233$ All would agree that drainage is necessary if the pylorus is scarred as a result of chronic ulceration.

On theoretical grounds it would appear that, at best, drainage is unnecessary, and may be harmful. McKelvey34 coined the term "gastric incontinence" to describe the rapid emptying of the denervated stomach in the erect position. This effect has been confirmed by others ${ }^{35-37}$ and may be caused by increased basal tone, impaired receptive relaxation, ${ }^{3738}$ or loss of the duodenal brake to gastric emptying. ${ }^{34}$ After oesophagectomy the denervated stomach is suspended within the chest and drainage would be expected to be rapid. This is supported by the experimental work of Shapiro et $a l^{39}$ and by clinical study. ${ }^{27}$ The performance of an unnecessary drainage procedure may predispose to reflux of duodenal juice ${ }^{40}$ resulting in a high incidence of gastritis, gastric erosions, and reflux oesophagitis ${ }^{38}$ which are otherwise unusual findings after oesophagectomy without drainage. ${ }^{27-40}$ It is feasible that suspending the denervated stomach within the chest, as after oesophagectomy, may exert a postural effect which to a greater or lesser degree may cancel out the known neural effects of vagotomy on gastric emptying.

The differential emptying rate of liquids and solids from the normal stomach is effected by the antrum, ${ }^{41}$ remains independent of the rate of gastric emptying and unaltered by pyloroplasty, ${ }^{42}$ and persists after vagotomy. ${ }^{43}$ Oesophagectomy for low lesions is accompanied by proximal gastrectomy and this portion of the stomach is concerned principally with the liquid phase of gastric emptying. ${ }^{6}$

Gastric emptying in the normal subject is known to be influenced by drugs ${ }^{11} 12$ or illness ${ }^{12} 13$ with consequences on drug absorption. The effect of vagotomy on small bowel absorption and motility is as yet unknown, but such studies as are available suggest there is little change in small intestinal absorption. ${ }^{44}$ Despite the conflicting theoretical considerations and the permanency of pyloric drainage, there are few studies of gastric emptying after oesophagogastrectomy and none concerned with the effect of disordered gastric emptying on drug absorption.

\section{Conclusion}

In this pilot study using an indirect assessment of gastric emptying of a small volume of liquid, oesophagogastrectomy did not markedly influence gastric emptying up to two years after operation.

We acknowledge gratefully the help given by the Nursing Staff of Ward A of King George V Hospital in the supervision and collection of specimens during the studies, and thank the Surgeons of the Oesophageal Unit, King George V Hospital for permission to study their patients. We would thank Miss Diana Maule and Mrs Jane Field, Brompton Hospital and Miss Margaret Toland, Cardiothoracic Unit, Glasgow Royal Infirmary, for their secretarial skills, and Mr D Ellis, Photographic Department, University College Hospital, for help in preparing the tables. Dr SW Nimmo, Senior Lecturer, Department of Anaesthetics, Western Infirmary, Glasgow, gave valuable advice in the construction of this study and the presentation of the results.

\section{References}

${ }^{1}$ Adams WE, Phemister DH. Carcinoma of the lower thoracic esophagus. Report of a successful resection and esophagogastrostomy. J Thorac Surg 1937-8;7:621-37.

${ }^{2}$ Lewis I. The surgical treatment of carcinoma of the oesophagus. Br J Surg 1947;34:18-31.

${ }^{3}$ Logan A. The surgical treatment of carcinoma of the oesophagus and cardia. J Thorac Cardiovasc Surg 1963; 46:150-61.

${ }^{4}$ Belsey R, Hiebert CA.An exclusive right thoracic approach for cancer of the middle third of the oesophagus. Ann Thorac Surg 1974;18:1-15.

${ }^{5}$ McKeown KC. Total three stage oesophagectomy for carcinoma of the oesophagus. Br J Surg 1976;63:259-62.

${ }^{6}$ Cooperman AM, Cook SA. Gastric emptying-physiology and measurement. Surg Clin North Am 1976;56:1277-87. 
7 Williams JA, Donovan IA, Gunn IF, Brown A, Harding LK. The effect of vagotomy on gastric emptying. Proc $R$ Soc Med 1973;66:1102-3.

${ }^{8}$ Cowley DJ, Vernon P, Jones T, Glass HI, Cox AG. Gastric emptying of solid meals after truncal vagotomy and pyloroplasty in human subjects. Gut $1972 ; 13: 176-81$.

- Heading RC, Tothill P, McLoughlin GP, Shearman DJC. Gastric emptying rate measurement in man: a double isotopic scanning technique for simultaneous study of solid and liquid phases. Gut 1974;15:841.

${ }^{10}$ Heading RC, Nimmo J, Prescott LF, Tothill P. The dependence of paracetamol absorption on the rate of gastric emptying. Br J Pharmacol 1973;47:415-21.

11 Nimmo WS, Heading RC, Wilson J, Tothill P, Prescott LF. Inhibition of gastric emptying and drug absorption by narcotic analgesics. Br J Clin Pharmacol 1975;2: 509-13.

12 Nimmo WS, Wilson J, Prescott LF. Narcotic analgesics and delayed gastric emptying during labour. Lancet $1975 ; \mathrm{i}: 890-3$.

${ }^{13}$ Nimmo WS. Drugs, diseases and altered gastric emptying. Clin Pharmacokin 1976;1:189-203.

14 Grimes DS, Goddard J. The effects of cigarette smoking on gastric emptying. Br Med J 1978;ii :460-1.

${ }^{15}$ Nimmo WS, Prescott LF. The influence of posture on paracetamol absorption. Br J Clin Pharmacol 1978;5: 348-9.

${ }^{16}$ Thomas BH, Coldwell BB. Estimation of phenacetin and paracetamol in plasma and urine by gas-liquid chromatography. J Pharm Pharmacol 1972;24:243.

17 Prescott LF. The gas-liquid chromatographic estimation of phenacetin and paracetamol in plasma and urine. $J$ Pharm Pharmacol 1971;23:111-5.

${ }^{18}$ Siegel S. Nonparametric statistics. New York: McGrawHill, 1956:116.

19 Thornton TF, Storer EH, Dragstedt LR. Supradiaphragmatic section of the vagus nerves. JAMA 1946; 130:764-71.

${ }^{20}$ Tanner NC. Vagotomy and pyloroplasty. Postgrad Med J $1950 ; 26: 575-6$.

${ }^{21}$ Weinberg JA. Pyloroplasty and vagotomy for duodenal ulcer. Current Problems in Surgery. April 1974;1-36

22 Brewer AL. Discussion of Thomas AN, Dedo HH. Pharyngogastrectomy for the treatment of severe caustic stricture of the pharynx and oesophagus. J Thorac Cardiovasc Surg 1977;73:817-24.

${ }^{23}$ Blades CV. Surgical Diseases of the Chest. St Louis: CV Mosby, 1961.

${ }^{24}$ Gibbon JH, Sabiston DC, Spencer FC. Surgery of the Chest. London: Saunders Publishing, 1969.

${ }^{25}$ Payne WS, Olsen AM. The Esophagus. Philadelphia: Lea and Febiger, 1974.

28 Collis JL. The surgical treatment of carcinoma of the oesophagus and cardia. Br J Surg 1971;58:801-4.
${ }^{27}$ Angorn IB. Oesophagogastrostomy without a drainage procedure in oesophagel carcinoma. Br J Surg 1975; $62: 601-4$

${ }^{28}$ Fisher RD, Brawley RK, Kieffer RF. Esophagogastrostomy in the treatment of carcinoma of the distal two thirds of the esophagus. Ann Thorac Surg 1972;14:658-70.

${ }^{29}$ Chung EP, Lawson RAM, Blesovsky A, Barnsley WC. Pyloromyotomy - a new technique in conjunction with oesophagectomy or repair of hiatus hernia with vagotomy. J Thorac Cardiovasc Surg 1971 ;61:282-6.

${ }^{30}$ Carey JS, Plested WG, Hughes RK. Esophagogastrectomy -superiority of the combined abdominal-right thoracic approach. Ann Thorac Surg 1972;14:59-68.

${ }^{31}$ Orringer MB, Sloan H. Substernal gastric by-pass of the excluded thoracic esophagus for palliation of esophageal carcinoma. J Thorac Cardiovasc Surg 1975;70:836-51.

${ }^{32}$ Royston CMS, Dowling BL. A combined synchronous technique for the McKeown three stage oesophagectomy. Br J Surg 1976;63:122-4.

${ }^{33}$ Akiyama $\mathrm{H}$, Hiyama $\mathrm{M}$, Hashimoto $\mathrm{C}$. Resection and reconstruction for carcinoma of the thoracic oesophagus. Br J Surg 1976;63:206-9.

${ }^{34}$ McKelvey STD. Gastric incontinence and post-vagotomy diarrhoea. Br J Surg 1970;57:741-7.

${ }^{35}$ Johnston D, Wilkinson AR. Vagotomy without drainage. Br J Surg 1970;57:289-96.

36 Colmer MR, Owen GM, Shields R. Patterns of gastric emptying after vagotomy and pyloroplasty. $\mathrm{Br}$ Med J 1973 ;ii :448-50.

37 Hancock BD, Bowen-Jones E, Dixon R, Testa T, Dymock IW, Cowley DJ. The effect of posture on gastric emptying of solid meals in normal subjects and after vagotomy. $\mathrm{Br}$ J Surg 1974;61:945-9.

${ }^{38}$ Hinder RA. Effect of posture on the emptying of the intrathoracic vagotomised stomach. Br J Surg 1976;63:581-4.

${ }^{39}$ Shapiro S, Hamlin D, Morgenstern L. The fate of the pylorus in oesophagoantrostomy. Surg Gynecol Obstet 1972;135:216-8.

${ }^{40}$ Collis JL. The long term clinical state after resection with gastro-oesophagostomy. In: Smith RA, Smith RE, eds. Surgery of the Oesophagus. London: Butterworth, 1972: 19-22.

${ }^{41}$ Hunt JH, Knox MT. Regulation of gastric emptying Handbook of Physiology. Section 6, vol 4, ch 94 Washington DC: American Physiological Society, 1968.

42 Heading RC, Tothill P, McLoughlin GP, Shearman DJC. Effects of gastric surgery on differential empty!ng of solid and liquid components of the gastric contents. Abstract. Br J Surg 1975;62:659.

${ }^{43}$ Donovan IA, Griffin DW, Harding LK, AlexanderWilliams J. Paradoxical gastric emptying after gastric surgery in man. Br J Surg 1974;61:916-7.

44 Williams JA, Cox AG. After Vagotomy. London:Butterworth, 1969:75. 